\title{
Professor Luiz Pasquali: Vida e Obra
}

\author{
Manuela Ramos Caldas Lins ${ }^{1}$ \\ ${ }^{1}$ Universidade de Brasília, DF, Brasil.
}

Resumo: Este artigo teve como objetivo explicitar, de forma resumida, aspectos relevantes da trajetória de um dos mais importantes propulsores da Avaliação Psicológica no Brasil: Prof. Dr. Luiz Pasquali. Filósofo, pedagogo, psicólogo e Professor Emérito da Universidade de Brasília, dedicou parte de sua vida ao Departamento de Psicologia Social e do Trabalho e ao Programa de Pós-graduação em Psicologia Social, do Trabalho e das Organizações, onde generosamente compartilhou seus conhecimentos em áreas diversas, como métodos de pesquisa, análises estatísticas e psicometria, contribuindo com a formação de dezenas de profissionais, professores e pesquisadores. Suas contribuições foram destacáveis, sobretudo, a partir dos anos 1990, quando consolidou seu Laboratório de Avaliação e Medida Psicológica, promovendo o primeiro curso de Especialização em Psicometria e tendo papel central na criação do Instituto Brasileiro de Avaliação Psicológica. Concluindo, para além de suas obras conhecidas, semeou generosidade, bom humor, fomentando o espírito científico colaborativo de seus seguidores.

Palavras-chave: Luiz Pasquali, Psicometria, Avaliação Psicológica, Análise Fatorial.

\section{Professor Luiz Pasquali: Life and Work}

Abstract: This article aimed to explain, in a summarized way, relevant aspects of the trajectory of one of the most important promoters of Psychological Assessment in Brazil: Prof. Dr. Luiz Pasquali. Philosopher, pedagogue, psychologist and Professor Emeritus of the University of Brasilia, he devoted part of his life to the Department of Social and Work Psychology and to the Graduate Program in Social, Work and Organizational Psychology. There, he generously shared his knowledge in diverse areas, such as research methods, statistical analysis, and psychometry, contributing to the training of dozens of professionals, professors, and researchers. His contributions were outstanding, especially since the 1990s, when he consolidated his Laboratory of Psychological Assessment and Measurement, promoting the first Specialization course in Psychometry, having a central role in the creation of the Brazilian Institute of Psychological Assessment. In conclusion, in addition to his well-known works, he sowed good-humor and generosity, fostering the collaborative scientific spirit of his followers.

Keywords: Luiz Pasquali, Psychometry, Psychological Assessment, Factor Analysis.

\footnotetext{
${ }^{1}$ Agradeço ao professor Valdiney Veloso Gouveia que contribuiu imensamente para a construção deste texto.
} 


\section{Profesor Luiz Pasquali: Vida y Obra}

Resumen: Este artículo tuvo como objetivo explicitar, de forma resumida, aspectos relevantes de la trayectoria de uno de los más importantes impulsores de la Evaluación Psicológica en Brasil: Prof. Dr. Luiz Pasquali. Filósofo, pedagogo, psicólogo y Profesor Emérito de la Universidad de Brasilia, el cual dedicó parte de su vida al Departamento de Psicología Social y del Trabajo y al Programa de Postgrado en Psicología Social, del Trabajo y de las Organizaciones, donde generosamente compartió sus conocimientos en áreas diversas, como métodos de investigación, análisis estadísticos y psicometría, contribuyendo a la formación de decenas de profesionales, profesores e investigadores. Sus contribuciones fueron destacables, sobre todo, a partir de los años noventa, cuando consolidó su Laboratorio de Evaluación y Medida Psicológica, promoviendo el primer curso de Especialización en Psicometría y teniendo un papel central en la creación del Instituto Brasileño de Evaluación Psicológica. Concluyendo, para allá de sus obras conocidas, sembró generosidad y buen humor, fomentando el espíritu científico colaborativo de sus seguidores.

Palabras clave: Luiz Pasquali, Psicometría, Evaluación Psicológica, Análisis Factorial.

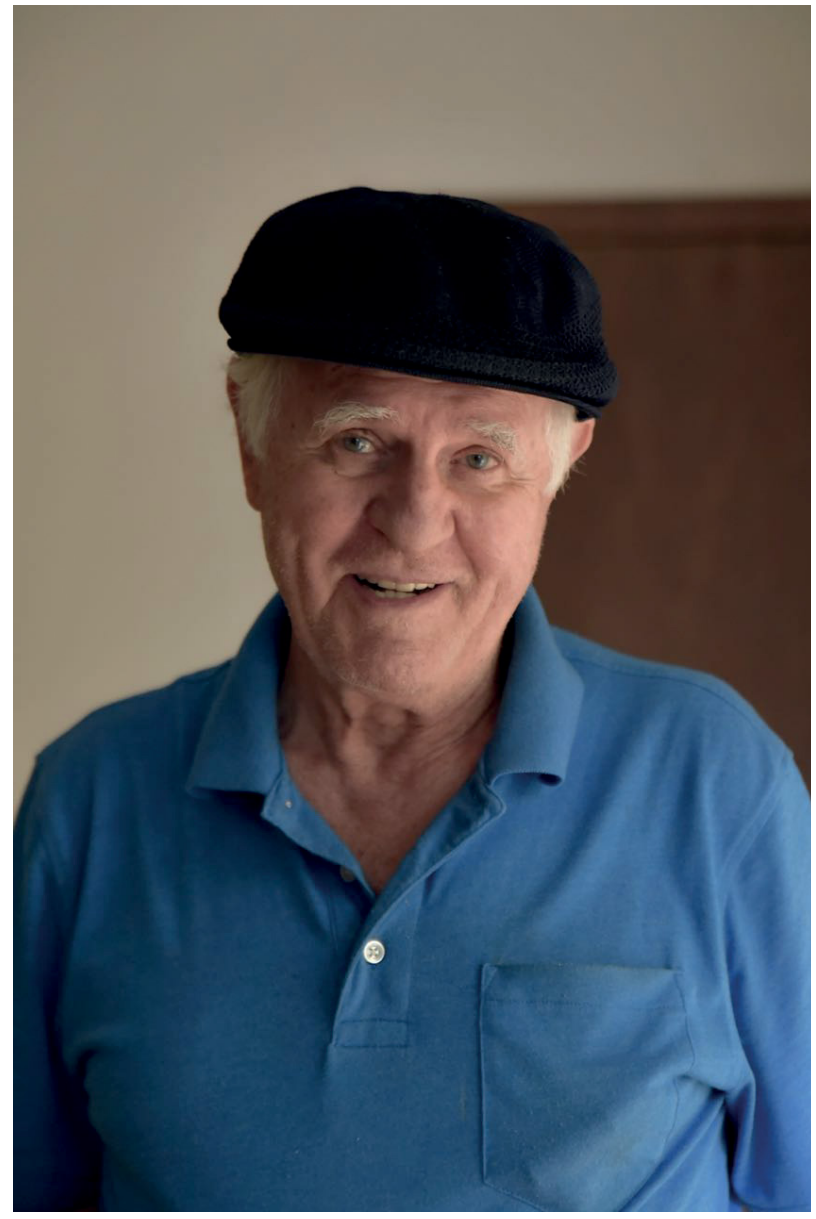

Convivi com pessoas inteligentes. Porém, apenas uma com processadores central e periférico: Luiz Pasquali! Trabalhei com você em dois momentos: quando, ainda um peste, ingressei no LabPAM, e, duas décadas após, na CCAP/CFP. Ficou uma certeza: você é iluminado! Ensinou-me de conceitos básicos em Psicometria a análises estatísticas avançadas. Quando me convidou a escrever um artigo, fiquei muito feliz; foi o meu primeiro e tive a chance de estar ao seu lado. Hoje, com lágrimas nos olhos, digo-lhe: Muito obrigado por tudo, meu eterno Mestre! (Valdiney Veloso Gouveia).

O professor Luiz Pasquali, aqui no Brasil, é sinônimo de Avaliação Psicológica. São tantas e tão significativas as suas contribuições para essa área, que não há como estudar esse tema sem entrar em contato com alguma de suas primorosas publicações. É com muita honra, prazer e orgulho que o Instituto Brasileiro de Avaliação Psicológica (IBAP) tem como um de seus fundadores esse nobre professor, que também foi o primeiro presidente da entidade (Monalisa Muniz). Fui aluna do Pasquali desde meu segundo semestre de graduação, em Psicologia, na UnB. Lá se vão décadas de vínculo, que se estenderam enquanto meu orientador de mestrado, doutorado e, hoje, 
como um amigo a quem tenho a alegria de dividir, enquanto colega de Departamento, a área de medidas. Acrescento a honra em ter assumindo um de seus maiores legados: o laboratório LabPAM. Ele foi um mestre inquestionavelmente importante para meu crescimento profissional e pessoal. Tenho tentado levar para meus alunos desafios importantes que me fez há época, quando desde a graduação teve a delicadeza de sentar ao meu lado para que eu pudesse construir meu primeiro teste e tecer minhas primeiras análises. E na Psicologia, registro minha admiração por seu papel ímpar na construção da psicometria no Brasil. Mas quem tem a honra de conviver com ele, precisa registrar uma frase importante para que possamos repensar nos nossos fazeres da academia: "nega, eu não sei de nada, estou aprendendo". A ti, Pasquali, minha gratidão! (Cristiane Faiad de Moura).

Conheci o professor Pasquali quando eu era recém-formada, em 1992, e atuava como professora de avaliação psicológica de uma instituição de ensino superior em Campinas, estado de São Paulo, ministrando disciplinas de Técnicas de Exames Psicológicos. Ele apresentou uma palestra em um auditório cedido pela Prefeitura de Campinas, sobre o panorama dos testes psicológicos. Causou grande impacto ao dizer que testes sem validade não deveriam ser ensinados, pois o cenário de instrumentos com qualidades psicométricas empiricamente demonstradas à época era absolutamente desanimador. Lembro-me do encantamento que senti ao assistir sua palestra e de como me senti desafiada a contribuir com o aprimoramento daquela área. Sua palestra serviu como mote para o aperfeiçoamento de minha formação profissional. Ao longo de toda minha inserção na pós-graduação, suas produções foram referências importantes, bem como ele serviu de inspiração em meu trajeto profissional (Ana Paula Porto Noronha).

O professor Luiz Pasquali é um tipo de gênio que não existe mais hoje em dia. É um trabalhador incansável, que estudou com profundidade todas as áreas do conhecimento. Ele transforma conceitos complexos de Psicometria em coisas simples, triviais e apaixonantes. Tudo isso com muita simpatia e humildade, de um jeito que faz todos à sua volta gostarem muito dele (Vicente Cassepp-Borges).
No Brasil, quando se fala em Psicometria e Avaliação Psicológica, é impossível não se lembrar do nome do Professor Luiz Pasquali. Isso reflete, certamente, seus ensinamentos, suas contribuições diversas, que ficaram registradas em instrumentos adaptados e construídos para a realidade brasileira, seus artigos e, sobretudo, livros, onde muitos de nós aprendemos. Expoente inconteste da área, tem trabalhado em prol da melhoria da formação profissional desde seu ingresso no universo acadêmico. Um entusiasta, sempre alegre e surpreendente com seus comentários brilhantes, foi um Professor à frente de seu tempo. Dominou como poucos os fundamentos de epistemologia, teoria da medida e computação, unidos todos em seus ensinamentos de diversos procedimentos de elaboração de medida e análise de dados. Conceitos complexos e pouco conhecidos no cenário nacional, foram generosamente traduzidos e compartilhados. Ele é um exemplo de dedicação e amor à academia. No presente artigo, tenho a honra de representar centenas de profissionais que gostariam de expressar seu reconhecimento e gratidão ao Mestre; o farei apresentando sua trajetória, porém reconheço que é muito pouco por tudo que ele tem feito pela Psicologia brasileira.

\section{Vida e família}

Luiz Pasquali nasceu em Gaurama, interior do Rio Grande do Sul, em 15 de dezembro de 1933. Filho de Ermínio Omobono Pasquali e Maria Caldato Pasquali; ele foi o segundo filho dentre 14 (nove irmãos e quatro irmãs) que tiveram seus pais. Casou-se com Concetta (Connie) Grace Pasquali, com quem teve dois filhos: Fábio Pasquali e Nilo Pasquali. É declarado avô coruja de quatro netos (Rafael, Gabriela, Luiz e Bruno). Atualmente reside em Brasília, cidade que o acolheu em meados dos anos 1970. A ciência e a religião nunca foram um problema em sua vida, que se harmoniza com os cuidados com sua chácara, onde cria suas galinhas e frutas.

\section{Formação acadêmica}

Concluiu diversas graduações, como Filosofia (1957; Instituto Franciscano de Filosofia, Paraná), Pedagogia (1961; Universidade Católica de Petrópolis, Rio de Janeiro) e Psicologia (1966; Université Catholique de Louvain, Bélgica). Um ano após ter concluído a formação em Psicologia, apresentou sua dissertação de Mestrado, intitulada "Symbolization of the image 
of God by the parental images: Genetic and differential study", sob orientação do Professor Antoine Vergote, na Université Catholique de Louvain. Três anos mais tarde, nesta mesma Universidade e também sob orientação de Professor Antoine Vergote, defendeu sua tese de Doutorado, que foi intitulada "The parental images and the concept of God: Formulation of an instrument of measure in the psychology of religion".

\section{Atuação profissional}

Logo após a obtenção do título de Doutor em Psicologia, em 1970 foi selecionado para trabalhar no Departamento de Psicologia da Grand Valley State University, no estado do Michigan, onde iniciou sua vida como docente respeitado. Ministrou nesta instituição disciplinas de Introdução à Psicologia e Higiene Mental, contribuindo com a formação de dezenas psicólogos estadunidenses.

Em 1973 decidiu se mudar dos Estados Unidos, construindo sua carreira acadêmica no Brasil. Seu primeiro vínculo como Professor foi na Pontifícia Universidade Católica do Rio Grande do Sul (PUC-RS), onde contribuiu com a criação e Coordenação do Mestrado em Psicologia. Naquela oportunidade ministrou disciplinas na graduação (História da Psicologia, Psicologia da Personalidade e Métodos de Pesquisa e Estatística) $\mathrm{e}$ orientou várias dissertações de Mestrado.

Em 1975, fruto de sua dedicação e trabalho constantes, foi convidado para se vincular ao Instituto de Psicologia da Universidade de Brasília (UnB). Não poderia imaginar, mas aquela seria sua casa durante muitos e valorosos anos. Na UnB ministrou dezenas de disciplinas na graduação e na pós-graduação, como Análise Fatorial em Psicologia, Métodos e Medidas em Psicologia Social, Métodos Inferenciais em Psicologia, Planejamento de Pesquisa, Psicometriae Técnicas de Exame Psicológico.

Contudo, o Professor Luiz Pasquali nunca se restringiu a ministrar aulas; ele sabia que poderia e deveria contribuir mais, sobretudo com a área de Avaliação Psicológica, que estava simplesmente estagnada. O descrédito dos testes no Brasil era evidente e as editoras faziam o que queriam; os instrumentos eram apenas traduzidos para o contexto local, utilizando normas de outros países. Os diversos problemas técnicos da área suscitavam críticas de todos os setores, não se observando alternativas. Naquele momento, juntaram-se alguns dos pesquisadores de maior impacto na área, a exemplo dos professores Dra. Solange Muglia Wechsler e Dr. Cláudio Simon Hutz, os quais começaram a definir e levar a cabo uma série de estratégias para alavancar a área.

Dentre as medidas acordadas pelos pesquisadores, estava a necessidade de fortalecer espaços de produção de conhecimento em Avaliação Psicológica. Nesta direção, Professor Luiz Pasquali, em 1988, contando com verbas da Financiadora de Estudos e Projetos (Finep), fundou o Laboratório de Psicologia, Avaliação e Medidas (LabPAM). Neste laboratório foram formados vários psicólogos, os quais perpetuaram a avaliação psicológica por diversos contextos em que atuam nas diferentes regiões do país. Além do cuidado com a formação nos níveis de graduação e pós-graduação, Professor Luiz Pasquali construiu e validou diversos instrumentos psicológicos, muitos dos quais se encontram aprovados para uso pelo Conselho Federal de Psicologia (CFP).

Em 1991, nosso Mestre se tornou Professor Titular de Psicologia da Universidade de Brasília, vindo a se aposentar em 2004, quando passou à condição de Pesquisador Associado do Programa de Pós-graduação em Psicologia Social, do Trabalho e das Organizações (PSTO). Entretanto, pouco tempo depois, em 2006, foi justamente reconhecido por seus pares, recebendo o título honorífico de Professor Emérito, publicamente justificado em decorrência dos seus valiosos serviços prestados à comunidade acadêmica. Por este mesmo motivo, em 2012, recebeu da Câmara Legislativa do Distrito Federal uma homenagem digna de seus legisladores: Moção de Louvor e Aplausos.

\section{Outras contribuições relevantes}

Professor Luiz Pasquali tem sido membro no Conselho Editorial de diversas revistas no cenário nacional, destacando-se Avaliação Psicológica, Boletim de Psicologia, Estudos de Psicologia (Campinas), Psicologia: Teoria e Pesquisa e Psicologia: Reflexão e Crítica. Além disso, tem contribuído como parecerista destas e tantas outras revistas (por exemplo, Revista Aletheia, Interação em Psicologia, Psico-USF).

Em 1997, durante a 27 ${ }^{\text {a }}$ Reunião Anual da Sociedade Brasileira de Psicologia (SBP), Professor Luiz Pasquali foi personagem importante na fundação do Instituto Brasileiro de Avaliação Psicológica (IBAP). De fato, ele foi o seu primeiro Presidente. É destacável o papel deste Instituto, que desde 2002 faz parte do Fórum de Entidades Nacionais da Psicologia, representando a Avaliação Psicológica. Além disso, o IBAP tem organizado diversos congressos da área, reunindo 
entidades locais e internacionais; em 2019 realizará o IX Congresso Brasileiro de Avaliação Psicológica.

Em 2006, já aposentado e em colaboração com Antônio Uchôa Pinheiro e Bartholomeu Tôrres Tróccoli, Professor Luiz Pasquali fundou a empresa LabPAM - Saber e Tecnologia de Avaliação. Este empreendimento foi sendo gerado a partir de suas experiências com a criação do Laboratório de Psicologia, Avaliação e Medidas, pertencente à UnB. O objetivo desta empresa foi disponibilizar à sociedade produtos e serviços concernentes à Avaliação Psicológica.

De 2001 a 2007, Professor Luiz Pasquali prestou serviço ao Centro de Seleção e de Promoção de Eventos (Cespe; atualmente Cebraspe), da Universidade de Brasília. Este Centro tem sido responsável por planejar e executar diversos concursos públicos, processos seletivos e vestibulares, além oferecer cursos de capacitação, treinamentos e pesquisa em avaliação. Durante o período que esteve vinculado ao Cespe, ele foi responsável por diversos processos avaliativos coletivos, tendo avaliado, em conjunto com sua equipe, mais de 50.000 candidatos.

Em 2002, contando com os seus colegas de Diretoria do IBAP, Professor Luiz Pasquali fundou a revista de Avaliação Psicológica, que segue sendo o veículo oficial deste Instituto para publicação de artigos nesta área. Nela têm sido priorizados os artigos sobre adaptação e construção de instrumentos de avaliação psicológica, dando ênfase a estudos empíricos que comprovem parâmetros das medidas. Entretanto, favorece igualmente ensaios e abordagens teóricas da Avaliação Psicológica e Psicometria, sendo fundamental para promover esta área enquanto ciência.

De 2014 a 2016, o Professor Luiz Pasquali compôs a Comissão Consultiva em Avaliação Psicológica (CCAP), criada pelo CFP, juntamente com seus colegas Cicero Emídio Vaz, Elton Hiroshi Matsushima, João Carlos Alchieri, José Neander Silva Abreu, Roberto Moraes Cruz e Valdiney Veloso Gouveia. Esta Comissão é responsável por discutir sobre processos avaliativos, propor normas técnicas e resoluções, cartilhas e outros recursos que promovam e assegurem a qualidade da Avaliação Psicológica no Brasil, desde sua elaboração, adaptação, comercialização e uso. Portanto, fundamental para assegurar o avanço desta área no Brasil.

Em 2018, juntamente com Bartholomeu Tôrres Tróccoli, Victor Mendonça Neiva e José Geraldo Maciel Júnior, o Professor Luiz Pasquali fundou a $P \& T$ Psychodata. Esta empresa foi pensada com os pro- pósitos de elaborar e fornecer testes psicométricos, realizar análises profissiográficas e mapeamento de competências organizacionais, fazendo uso de técnicas avançadas de psicometria, tais com a Teoria de Resposta ao Item (TRI) e a Avaliação de Programas com ênfase no modelo lógico.

\section{Publicações de artigos, livros e capítulos de livros}

Professor Luiz Pasquali publicou 78 artigos científicos, sendo o primeiro há quase meio século [Vergote, A., \& Pasquali, L. (1969). Concept of God and parental images. Journal for the Scientific Study of Religion, 8 (1), 79-87], destacando-se alguns dos jornais de impacto em Psicologia (por exemplo, Developmental Psychology, International Journal of Behavioral Development, Perceptual and Motor Skills). Conta, ademais, com a publicação de 36 capítulos de livro.

O Professor possui diversos livros publicados na área de Avaliação Psicológica, sendo o primeiro deles Instrumentos Psicológicos: Manual Prático de Elaboração (1999). Porém, diversas outras obras foram escritas desde então, destacando-se Técnicas de Exame Psicológico - TEP (2001), Os Tipos Humanos - A Teoria da Personalidade (2003), Análise Fatorial para Pesquisadores (2005), Datiloscopia-A Determinação dos Dedos (2006), TRI: Teoria de Resposta ao Item - Teoria, Procedimentos e Aplicações (2007), A ciência da Mente - A Psicologia à Procura do Objeto (2008), Psicometria: Teoria dos Testes na Psicologia e Educação (2009), Instrumentação Psicológica - Fundamentos e Práticas (2010), Delineamento de Pesquisa em Ciência (Volumes 1 e 2) (2015) e TEP Técnicas de Exame Psicológico: Os Fundamentos (2016).

\section{Conferências, relatórios técnicos e orientações}

Professor Luiz Pasquali conta com cerca de 20 trabalhos técnicos realizados para entidades governamentais e não governamentais no país, prestando serviço à Polícia Militar do Distrito Federal, à Polícia Federal e ao Centro Integrado de Defesa Aérea e Controle de Tráfego Aéreo, por exemplo. Como convidado, ministrou diversas palestras em abertura de eventos científicos, além de contar com mais de 100 participações em eventos nacionais e internacionais. Destaca-se, ainda, em sua trajetória, a orientação de 60 dissertações de Mestrado e 16 teses de Doutorado defendidas por seus orientandos. 


\section{Considerações finais}

As contribuições do Professor Luiz Pasquali não deixam dúvida: é uma pessoa iluminada, um exemplo de competência e dedicação. Sempre engajado, disponível e entusiasmado com a ciência, a Psicologia e, particularmente, a Avaliação Psicológica. Quem convive ou conviveu com ele sabe de sua conduta exemplar e invariável: chega cedo ao trabalho, senta em sua cadeira e escreve, escreve, escreve... Sempre tem algo mais a dizer, mas de espírito aberto para brincar quando alguém interrompe o seu pensamento. Naquele instante, para a maior de nós, significaria perder o dia, paralisar o trabalho. E para o Professor Luiz Pasquali? Não tenha dúvida, de algum lugar ele tira uma nova ideia, aproveita a interrupção para compartilhar conhecimentos e propor um novo livro.

Um Mestre não se qualifica apenas por sua disponibilidade em aprender, mas em se renovar. Precisamente, este é o espírito do Professor Luiz Pasquali. Está sempre disposto a ensinar a quem quer que seja, mas cada dia mais aberto a ouvir e aprender; um estilo brincalhão, mas sempre tratando de assuntos sérios; não se sabe de pessoa que tenha ido bater a sua porta e não tenha saído feliz, satisfeita com alguma ação ou ideia apresentada por ele. Certamente, trata-se de um dos maiores e mais humildes pesquisadores brasileiros. Professor e Pesquisador, mas, acima de tudo, Humano; impossível alguém ter discutido com ele, improvável que tenha feito algo para prejudicar qualquer pessoa. Precisamos de mais Pasqualis no mundo acadêmico! Quem o vê se deliciando com um peixe frito e abacaxi, logo tomando uma "lapada de cana" (aguardente) em algum restaurante simples, não imagina que ali está um dos personagens mais importantes da Avaliação Psicológica brasileira.
Finalmente, na linha do que antes comentei, se o que pretendo é retratar adequadamente o Professor Luiz Pasquali, não posso me ater à sua trajetória acadêmica, pois tem sido também uma figura folclórica. Portanto, preciso transpor os muros da academia e falar de um ser humano doce, calmo, paciente, lindo e brincalhão; certamente cada um de nós teria uma anedota ou um episódio curioso envolvendo o Mestre. Impossível ver alguém usar ou falar sobre rapé sem vir à cabeça sua imagem; de modo semelhante, seu suspensório e sua boina tão característicos. Falar de um minhocário muito bem cuidado pelas mãos de um marido, pai e avó inestimável; é falar da obra do Professor Luiz Pasquali, nosso eterno Mestre, que com sua graça e dedicação, formou uma família extensa composta por diversos pesquisadores de renome nos cenários nacional e internacional.

Mestre, muito obrigado por existir em nossas vidas! Agradecemos por todos os ensinamentos. Poder conviver e aprender com você foi uma das maiores honras que nos foi concedida. Você nos ensinou sobre Psicologia e Avaliação Psicológica; porém, foi muito além disso, mostrando-nos como é possível ser tão grande em um mundo por vezes mesquinho, mas sem jamais deixar de ser humilde, paciente, persistente e, acima de tudo, generoso. Você foi e continua sendo exemplo. Perdoe-nos por nossas falhas, por não termos sua nobreza; o que mais desejamos é poder um dia retribuir ao menos um pouco de tanto que fez por nós, não apenas indivíduos, mas a Psicologia como um todo. Que sorte e honra a nossa, por termos sido seus aprendizes!!!

\section{Referências}

Pasquali, L. (1999). Instrumentos Psicológicos: Manual Prático de Elaboração. Brasília: LabPAM/IBAPP.

Pasquali, L. (2001). Técnicas de Exame Psicológico - TEP. São Paulo: Conselho Federal de Psicologia/Casa do Psicólogo.

Pasquali, L. (2003). Os Tipos Humanos - A Teoria da Personalidade. Brasília: LabPAM.

Pasquali, L. (2005). Análise Fatorial para Pesquisadores. Brasília: LabPAM.

Araujo, M. E. C. \& Pasquali, L. (2006). Datiloscopia - A Determinação dos Dedos. Brasília: LabPAM.

Pasquali, L. (2007). TRI: Teoria de Resposta ao Item - Teoria, Procedimentos e Aplicações. Brasília: LabPAM.

Pasquali, L. (2008). A ciência da Mente - A Psicologia à Procura do Objeto. Brasília, DF: Autor.

Pasquali, L. (2009). Psicometria: Teoria dos Testes na Psicologia e Educação. Petrópolis, RJ:Vozes.

Pasquali, L. (2010). Instrumentação Psicológica - Fundamentos e Práticas. Porto Alegre, RS: Artmed. 
Pasquali, L. (2015). Delineamento de Pesquisa em Ciência (Volume 1). São Paulo, SP: Vetor.

Pasquali, L. (2015). Delineamento de Pesquisa em Ciência (Volume 2). São Paulo, SP: Vetor.

Pasquali, L. (2016). TEP - Técnicas de Exame Psicológico: Os Fundamentos. São Paulo, SP: Vetor.

\section{Manuela Ramos Caldas Lins}

Doutora em Psicologia pela Universidade de Brasília, DF, Brasil. Tem interesse nas seguintes áreas e temáticas: cognição, emoções, psicometria, avaliação psicológica e neuropsicológica, neurodesenvolvimento infantil e deficiência visual.

E-mail: manuela_rcl@hotmail.com

Endereço para envio de correspondência:

SEPN 707/907, Asa Norte, Brasília, DF. CEP: 70790- 075

Recebido: $23 / 07 / 2018$

Aprovado: 07/08/2018

Received:07/23/2018

Approved: 08/07/2018

Recibido: $23 / 07 / 2018$

Aceptado: 07/08/2018

Como citar: Lins, M. R. C. (2018). Professor Luiz Pasquali:Vida e Obra. Psicologia: Ciência e Profissão, 38(n.spe), 175-181. https://doi.org/10.1590/1982-3703000208980

How to cite: Lins, M. R. C. (2018).Professor Luiz Pasquali: Life and Work. Psicologia: Ciência e Profissão, 38(n.spe), 175-181. https://doi.org/10.1590/1982-3703000208980

Cómocitar:Lins, M.R.C. (2018).Profesor LuizPasquali:VidayObra. Psicologia:Ciênciae Profissão, 38(n.spe), 175-181. https://doi.org/10.1590/1982-3703000208980 